\title{
Does social capital influence purpose in life and life satisfaction among Japanese health-literate professionals?
}

\author{
Nobutaka Hirooka $^{1}$ (D) $\cdot$ Takeru Kusano $^{1} \cdot$ Shunsuke Kinoshita $^{1} \cdot$ Ryutaro Aoyagi $^{1} \cdot$ Kohei Saito $^{1}$. \\ Hidetomo Nakamoto ${ }^{1}$
}

Accepted: 11 May 2021 / Published online: 18 May 2021

(C) The Author(s) 2021

\begin{abstract}
A strong sense of purpose and satisfaction in life is associated with multiple health benefits. There is also evidence to suggest that social capital predicts better health indicators. While both social capital and purpose and satisfaction in life direct better health, the relationship between social capital and purpose and satisfaction in life in terms of health, remains unclear. A retrospective cohort study was conducted on Japanese health management professionals $(N=4820)$. We analyzed the cohort's demographics and reported changes in social capital (social engagement and trust), purpose in life, and life satisfaction using self-reported questionnaires and the Ikigai-9 scale. The cohort was categorized into group 1 (neither changes), group 2 (one changes), and group 3 (both change), based on the number of changes reported in social capital. Purpose in life and life satisfaction scores were then compared among the three groups. The purpose in life score (SD [standard deviation]) for groups 1, 2, and 3 was 30.7 (6.0), 32.5 (5.6), and 35.6 (5.2), respectively. Life satisfaction scores (SD) for groups 1,2 and 3 were $3.35(0.8), 3.67(0.8)$, and $4.26(0.7)$, respectively. We found a statistically significant difference in purpose and satisfaction in life among the three groups $(F(2)=361.4, p<0.001$ and $F(2)=$ 703.9, $p<0.001$ ). Social capital was associated with purpose and satisfaction in life among health-literate professionals. Strengthening social capital may increase individual purpose and satisfaction in life and ultimately yield better health.
\end{abstract}

Keywords Social capital $\cdot$ Purpose in life $\cdot$ Satisfaction in life $\cdot$ Health-literate

\section{Introduction}

Purpose in life, or Ikigai in Japanese, has been investigated within the context of health and disease prevention. Ikigai is defined as something to live for, or the joy and goal of living (Tanno et al., 2009; Sone et al., 2008). Various studies show that a strong sense of purpose in life is associated with multiple health benefits (Cohen et al., 2016; Roepke et al., 2014; Wood and Joseph, 2010; Alimujiang et al., 2019). An enhanced purpose in life seems to result in better health outcomes (Krause, 2009; Musich et al., 2018). Previous Japanese studies show an association between purpose in life and all-cause mortality as well as cause-specific mortality, such as cardiovascular diseases (Koizumi et al., 2008). Similarly, life satisfaction has also been

Nobutaka Hirooka

nkaorohi@saitama-med.ac.jp

1 Department of General Internal Medicine, Saitama Medical University, Morohongo 38, Moroyama-chou, Iruma-gun, Saitama 350-0495, Japan investigated in relation to health outcomes (Boehm et al., 2011; Diener and Chan, 2011; Xu and Roberts, 2010; KoivumaaHonkanen et al., 2000). Both purpose in life and life satisfaction are part of individuals' well-being (Steptoe, 2019; Greenfield and Marks, 2004). In addition to the health benefits, a strong sense of purpose in life and life satisfaction are the goals of the national health campaign, Health Japan twenty-first century (HJ21); this campaign regards well-being as the foundation of human life (Ministry of Health, Labour, and Welfare, 2012), which can also be increased by appropriate intervention (Sin and Lyubomirsky, 2009; Kashaniyan and Khodabakshi, 2015). HJ21 has been implemented to create a society where all nationals can live a healthy and purposeful life and with satisfaction.

Engaging community and society helps individuals to gain Ikigai (Ishizaki et al., 2000; Suzuki and Shibata, 2003). The national health promotion campaign in Japan recommends engaging communities. Coleman considered social capital as a level of trust and reciprocity among community members (Coleman, 1990). Putnam built on Coleman's perspective and studied social trust and civic engagement. Social capital comprises structural and cognitive dimensions (Putnam, 1993), and 
is also defined as resources - for example, trust, norms, and the exercise of sanctions - that are available to members of social groups (Porta, 2014; Villalinga-Olives and Kawachi, 2015). HJ21 advocates for community engagement, an aspect of social capital and a factor of importance in increasing purpose in life and life satisfaction, in addition to promoting health through lifestyle management to avoid lifestyle-related diseases (Ministry of Health, Labour, and Welfare, 2012; Udagawa et al., 2008). Many studies and systematic reviews reveal good evidence to suggest that social capital predicts better health indicators. These include mental health, physical health, and mortality (Ehsan et al., 2019; Gilbert et al., 2013; Moore and Kawachi, 2017).

Although many studies show that social capital, purpose in life, and life satisfaction influence individual health, the relationship between aspects of social capital (trust and social engagement) in national health promotion campaigns such as HJ21, purpose in life, and life satisfaction, remains unclear. Understanding the relationships between social capital and purpose in life and social capital and life satisfaction would be valuable for planning health promotion interventions in national health campaigns. This study aims to investigate the extent to which purpose in life and life satisfaction are influenced by strengthening social capital among a highly healthliterate Japanese population.

\section{Method}

\section{Study Design}

The design was a retrospective cohort study among professional specialists in health management. We surveyed health perception and stress through a questionnaire similar to the one used in the HJ21 (National Institute of Health and Nutrition, 2013). We also used the Ikigai-9 scale, a validated Japanese tool to measure purpose in life (Imai et al., 2012). Lastly, we used self-administered questionnaires to record changes in trust and social engagement. All questionnaires were administered at the time when the study participants were enrolled. This study was approved by the Ethics Committee of Saitama Medical University (ID 896, 2018).

\section{Study Participants}

A total of 4820 certified professional specialists in health management agreed to participate in this survey. They actively pursued professional growth by continuing their professional education provided by the Japanese Association of Preventive Medicine for Adult Disease (JAPA; JAPA, n.d.). Candidates are registered as health management specialists after passing a written examination and their certification program is sponsored by the Japanese Ministry of Education, Culture, Sports, Science, and Technology. Professional specialists of health management are required to engage the community and the society they live in and promote health. JAPA encourages specialists to participate in numerous activities by enabling them to provide health promotion workshops, speeches, and activities as they are certified in multiple areas of study, including health promotion, lifestyle diseases, mental health, nutrition, environment and health, physical activity and exercise, emergency medicine and life support, and health care system (JAPA n.d.).

\section{Variables and Measurements}

The variables measured in this study were demographic data, perception of stress and health, changes in trust and social engagement after being certified, and purpose in life, using a formerly validated tool (Ikigai-9; Imai et al., 2012). The Cronbach's $\alpha$ for the Ikigai- 9 was 0.87 , showing adequate reliability and validity and confirming it to be useful for measuring purpose in life. Life satisfaction was also measured using a 5-point Likert scale questionnaire with scores being 1 (extremely satisfied), 2 (satisfied), 3 (neither satisfied nor dissatisfied), 4 (dissatisfied), and 5 (extremely dissatisfied). Changes in trust and social engagement after being certified as professional specialists of health management were also measured using a 5point Likert scale questionnaire with scores being 1 (significantly increased), 2 (somewhat increased), 3 (no change), 4 (somewhat decreased), and 5 (significantly decreased). Based on the number of increases (on account of "significantly increased" and "somewhat increased") both for trust and social engagement, we made changes to the grouping. Groups 1, 2, and 3 indicate no increase in trust or social engagement, increase in either trust or social engagement, and increase in both trust and social engagement, respectively. Ikigai-9 consists of nine questions on various life purposes and each question has five scales ranging from 1 (strongly disagree) to 5 (strongly agree). The total score of Ikigai- 9 was calculated by adding all nine scores; age, weight, height, BMI, purpose in life, and life satisfaction scores were numeric.

\section{Analysis}

Descriptive statistics (mean, average, standard deviation [SD], range) were used to describe the characteristics of the study participants. The proportion of changes in trust and social engagement were calculated in total and among the three groups. Differences in Ikigai-9 scores were investigated among the three groups with changes in the aspects of social capital with ANOVA test (Model 1). ANCOVA tests were performed to examine the association between social capital change and purpose in life. Two models were fit: Model 2 was adjusted for age, sex, and residence, while Model 3 was adjusted for stress and perceived health condition in addition to the variables adjusted for in Model 2. In addition, differences in life satisfaction scores 
were investigated among the three groups with changes in aspects of social capital with ANOVA test (Model 4). ANCOVA tests were also performed to examine the association between social capital change and life satisfaction. Two models were fit: Model 5 was adjusted for age, sex, and residence, while Model 6 was adjusted for stress and perceived health condition, in addition to the variables adjusted in Model 5. All statistical tests were two-tailed. IBM SPSS Statistics (Version 26.0. Armonk, NY, USA) was used for the analyses.

\section{Results}

\section{Descriptive}

Table 1 shows the demographics and characteristics of social capital of the total and of the three groups. The purpose in life scores (SD) of groups 1, 2, and 3 were 30.7 (6.0), 32.5 (5.6), and 35.6 (5.2), respectively. Life satisfaction scores (SD) of the groups 1, 2, and 3 were $3.35(0.8), 3.67(0.8)$, and 4.26 $(0.7)$, respectively.

\section{Analysis of Purpose in Life among the Groups}

We found a statistically significant difference in purpose in life among the three groups $(F(2)=361.4, p<0.001)$. The covariates in Model 2, age, and gender were significantly related to the purpose in life score, $F(1)=61.4, p<0.001$; $F(1,4814)=34.1, p<0.001$, respectively. There was also a significant effect of the number of changes in social capital on purpose in life score after controlling for the effect of age, gender, and residence, $F(2)=324.9, p<0.001$. Similarly, the covariates in Model 3, age, gender, stress, and health perception, were significantly related to purpose in life score (all $p$ values $<0.001)$. After controlling for all the covariates, there was a significant effect of the number of changes in social capital on purpose in life score, $F(2)=308.7, p<0.001$. Bs and $t$-statistics of the ANCOVA are shown in Table 2.

\section{Analysis of Life Satisfaction among the Groups}

The life satisfaction scores showed statistically significant differences among the groups $(F(2)=703.9, p<0.001)$. All the covariates in Model 5, age, gender, and residence were nonsignificantly related to life satisfaction. There was a significant effect of the number of changes in social capital on life satisfaction after controlling for the effect of age, gender, and residence, $F(2)=676.9, p<0.001$. The covariates in Model 6, stress and health perception, were significantly related to life satisfaction, $F(1)=10.7, p<0.001$, and $F(1)=11.6, p<0.001$, respectively. After controlling for all the covariates, there was a significant effect of the number of changes in social capital on the life satisfaction score, $F(2)=659.6 .7, p<0.001 . B$ and $t$ statistics of the ANCOVA are shown in Table 3.

\section{Discussion}

The results of this study indicate that increasing social engagement and a sense of trust can exert a positive influence on purpose in life and life satisfaction. To the best of our knowledge, this is the first study to show that enhanced social capital benefits an individual's purpose and satisfaction in life, in agreement with the national health promotion campaign HJ21. These results support the notion that social capital promotes health through purpose in life and life satisfaction. Comparably, many studies have shown a positive effect of purpose in life and life satisfaction on health outcomes (Cohen et al., 2016; Roepke et al., 2014; Wood and Joseph, 2010; Alimujiang et al., 2019).

Social capital has been shown to be associated with purpose in life in specific populations, such as people living with HIV and people affected by disasters (Hussen et al., 2014; Takahashi et al., 2015). Social capital and purpose in life have been thoroughly investigated separately and have been accepted as strong factors in determining health outcomes. However, few studies have investigated how these two factors interact with health outcomes. Thus, this study sheds light on an important way to promote health; the positive effect of social capital on purpose and satisfaction in life indicates potential synergistic influence while planning interventions for health promotion, as each has a positive effect on health.

The results indicating a positive relationship between social capital and life satisfaction deserve particular attention. There are many studies indicating the association between social capital and life satisfaction (Rodríguez-Pose and von Berlepsch, 2014; Leung et al., 2011; Winkelmann, 2009). There are also studies showing differences in the association between social capital and life satisfaction among different populations, in terms of variables such as gender, countries, or regions (Elgar et al., 2011). In Japan, a previous study indicated a positive association between social capital and life satisfaction in a nationwide survey. The Japanese participants, with extensive training in healthrelated areas, included multiple generations and both genders, and showed a positive association firmly extended the validity of the results from previous study. The extent of the association between social capital and life satisfaction that applies to other settings needs to be understood to better target health promotion.

There is no established theory or explanation for the mechanisms linking social capital and changes in purpose in life or social capital and life satisfaction. As discussed previously, there exists an inconsistency in the results from evaluating the association between social capital and life satisfaction. To confirm that social capital is attributed to purpose in life and life satisfaction (Elgar et al., 2011; Zou et al., 2018), further research is needed to elucidate the mechanistic and causal links 
Table 1 Demographic characteristics of participants $(N=4820)$

\begin{tabular}{|c|c|c|c|c|}
\hline & Total & Group 1 & Group 2 & Group 3 \\
\hline \multicolumn{5}{|l|}{ Sex } \\
\hline Male & 1630 & 454 & 368 & 808 \\
\hline Female & 3190 & 908 & 731 & 1551 \\
\hline Total & 4820 & 1362 & 1099 & 2359 \\
\hline \multicolumn{5}{|l|}{ Age range } \\
\hline$<30$ years & $129(2.7)$ & $52(3.8)$ & $38(3.5)$ & $39(1.7)$ \\
\hline 30-39 years & $372(7.7)$ & $141(10.4)$ & $90(8.2)$ & $141(6.0)$ \\
\hline $40-49$ years & $930(19.3)$ & $289(21.2)$ & $224(20.4)$ & 417 (17.7) \\
\hline $50-59$ years & $1541(32.0)$ & 445 (32.7) & $382(34.8)$ & $714(30.2)$ \\
\hline $60-69$ years & $1291(26.8)$ & $331(24.3)$ & $280(25.4)$ & $680(28.8)$ \\
\hline 70-79 years & $489(10.1)$ & $97(7.1)$ & $73(6.6)$ & $319(13.5)$ \\
\hline$\geqq 80$ years & $68(1.4)$ & $7(0.5)$ & $12(1.1)$ & $49(2.1)$ \\
\hline Age; Ave years (SD) & $55.4(12.2)$ & $53.1(12.1)$ & $53.9(12.0)$ & $57.4(12.0)$ \\
\hline \multicolumn{5}{|l|}{ Stress $(\%)$} \\
\hline High & 20.4 & 25.9 & 23.9 & 15.6 \\
\hline Moderate & 54 & 53.1 & 54.5 & 54.3 \\
\hline Low & 21.8 & 18.8 & 17.7 & 25.3 \\
\hline None & 3.7 & 2.2 & 3.6 & 4.7 \\
\hline Health perception (perceived "healthy"; \%) & 93.7 & 91.6 & 93.1 & 95.2 \\
\hline \multicolumn{5}{|l|}{ Trust $(\%)$} \\
\hline Increased significantly & 9.0 & 0.0 & 0.5 & 18.2 \\
\hline Increased somewhat & 43.5 & 0.2 & 15.2 & 81.7 \\
\hline No change & 47.3 & 99.3 & 84.2 & 0.1 \\
\hline Decreased somewhat & 0.1 & 0.2 & 0.0 & 0.0 \\
\hline Decreased significantly & 0.0 & 0.1 & 0.0 & 0.0 \\
\hline \multicolumn{5}{|l|}{ Social engagement $(\%)$} \\
\hline Increased significantly & 16.2 & 0.1 & 5.0 & 30.8 \\
\hline Increased somewhat & 52.0 & 0.2 & 79.3 & 69.1 \\
\hline No change & 31.6 & 98.9 & 15.6 & 0.1 \\
\hline Decreased somewhat & 0.1 & 0.3 & 0.1 & 0.0 \\
\hline Decreased significantly & 0.1 & 0.4 & 0.0 & 0.0 \\
\hline Purpose in life score & $33.50[33.3-33.7]$ & $30.7[30.4-31.0]$ & $32.5[32.1-32.8]$ & $35.6[35.4-35.8]$ \\
\hline Satisfaction score & $3.87[3.84-3.89]$ & $3.4[3.3-3.40]$ & $3.67[3.6-3.7]$ & $4.3[4.2-4.30]$ \\
\hline
\end{tabular}

Table 2 ANCOVA analysis of purpose in life among the groups by social capital changes

\begin{tabular}{llll}
\hline & Model 1 & Model 2 & Model 3 \\
& $B$, t-statistic & $B$, t-statistic & $B$, t-statistic \\
\hline Group 1 & ref. & ref. & ref. \\
Group 2 & $3.13,15.5^{* * * *}$ & $2.95,14.6^{* * * *}$ & $2.73,14.1^{* * * *}$ \\
Group 3 & $4.90,30.1^{* * *}$ & $4.67,24.7^{* * *}$ & $4.39,24.1^{* * *}$ \\
\hline
\end{tabular}

$* * * p<.001$. ref. indicates reference

Model 1 adjusts for no variable, Model 2 adjusts for age, gender, and residence, and Model 3 adjust for stress and health perception in addition to variables in Model 2

ref. indicates reference
Table 3 ANCVA analysis of life satisfaction among the groups by social capital changes

\begin{tabular}{llll}
\hline & Model 4 & Model 5 & Model 6 \\
& $B$, t-statistic & $B$, t-statistic & $B$, -statistic \\
\hline Group 1 & ref. & ref. & ref. \\
Group 2 & $0.60,21.9^{* * *}$ & $0.59,21.6^{* * *}$ & $0.58,21.1^{* * *}$ \\
Group 3 & $0.91,36.1^{* * *}$ & $0.91,35.5^{* * *}$ & $0.89,34.8^{* * *}$ \\
\hline
\end{tabular}

$* * * p<.001$. ref. indicates reference

Model 4 adjusts for no variable, Model 5 adjusts for age, gender, and residence, and Model 6 adjust for stress and health perception in addition to variables in Model 5 
between social capital, purpose in life, and life satisfaction regarding lifestyle, and to formulate more effective interventions in the context of HJ21. Importantly, HJ21's goals are to prevent diseases, increase health and longevity, and foster purpose in life and quality of life, including life satisfaction, by promoting healthy lifestyles and enriching social capability (Komiyama, 2012). To accomplish these goals, effective interventions are necessary. As the association between social capital and purpose in life and between social capital and life satisfaction were positive in our study and the effect of purpose in life and life satisfaction on health is known, social capital could be a prominent target for health promotion.

There are several limitations to this study. First, reporting bias may play a role in the analysis because of self-administration. Future studies may corroborate the measuring social capital using robust approaches and objective measurement to determine if the changes measured with objective record increase purpose in life or life satisfaction. Second, although several variables were adjusted in the analysis, other confounding variables, such as income, family, and marital status, may influence the association. Family, including marriage, seems to be a part of social capital. We did not include these in the analysis as covariates because of the potential collinearity. Nevertheless, this study has several strengths. First, we considered two dimensions of social capital, whereas the majority of previously reported studies on social capital consider only one dimension (Rodríguez-Pose and von Berlepsch, 2014). This widens the evidence of social capital on health. Second, this is a large nationwide cohort study, and that characteristic increases its external validity.

\section{Conclusion}

Strengthening social capital may increase individual purpose in life and life satisfaction. Social capital, purpose in life, and life satisfaction can be promising targets at a national level and interventions related to these factors are recommended to be widely incorporated into national health promotion plans; however, there remains a need to further investigate the mechanism of correlation between social capital and purpose in life and between social capital and life satisfaction, individually.

Acknowledgements We would like to thank board members of the Japanese Association of Preventive Medicine for Adult Disease; Takeshi Sano, Reiko Yasumura, Yuji Maeyama, who supported the study. We also would like to thank Editage (www.editage.com) for English language editing.

Code Availability Code is available from the corresponding author upon reasonable request.

Authors' Contributions Conceptualization, Nobutaka Hirooka and Takeru Kusano; data curation, Nobutaka Hirooka, Takeru Kusano,
Ryutaro Aoyagi, and Kohei Saito; formal analysis, Nobutaka Hirooka and Takeru Kusano; investigation, Nobutaka Hirooka, Takeru Kusano, Shunsuke Kinoshita, Ryutaro Aoyagi, Kohei Saito; methodology, Nobutaka Hirooka and takeru Kusano; project administration, Nobutaka Hirooka and Hidetomo Nakamoto; resources, Nobutaka Hirooka and Hidetomo Nakamoto; supervision, Hidetomo Nakamoto; validation, all authors; writing - original draft preparation, Nobutaka Hirooka; writing - review and editing, all authors.

Data Availability Data and material are available from the corresponding author upon reasonable request.

\section{Declarations}

Ethics Approval All the procedures performed in this study including human participants was in accordance with the ethical standards of the institutional and/or national research committee and with the 1964 Declaration of Helsinki and its later amendments or comparable ethical standards. The study was approved by the Ethics Committee of Saitama Medical University.

Consent to Participate Informed consent was obtained from all individual participants included in the study.

Conflict of Interest The authors declare that they have no conflict of interest.

Open Access This article is licensed under a Creative Commons Attribution 4.0 International License, which permits use, sharing, adaptation, distribution and reproduction in any medium or format, as long as you give appropriate credit to the original author(s) and the source, provide a link to the Creative Commons licence, and indicate if changes were made. The images or other third party material in this article are included in the article's Creative Commons licence, unless indicated otherwise in a credit line to the material. If material is not included in the article's Creative Commons licence and your intended use is not permitted by statutory regulation or exceeds the permitted use, you will need to obtain permission directly from the copyright holder. To view a copy of this licence, visit http://creativecommons.org/licenses/by/4.0/.

\section{References}

Alimujiang, A., Wiensch, A., Boss, J., Fleischer, N. L., Mondul, A. M., McLean, K., Mukherjee, B., \& Pearce, C. L. (2019). Association between life purpose and mortality among US adults older than 50 years. JAMA Network Open, 2(5), e194270. https://doi.org/10.1001/ jamanetworkopen.2019.4270.

Boehm, J. K., Peterson, C., Kivimaki, M., \& Kubzansky, L. D. (2011). Heart health when life is satisfying: Evidence from the Whitehall II cohort study. European Heart Journal, 32, 2672-2677. https://doi. org/10.1093/eurheartj/ehr203.

Cohen, R., Bavishi, C., \& Rozanski, A. (2016). Purpose in life and its relationship to all-cause mortality and cardiovascular events: A meta-analysis. Psychosomatic Medicine, 78(2), 122-133. https://doi. org/10.1097/PSY.0000000000000274.

Coleman, J. S. (1990). Foundations of social theory. Belknap Press of Harvard University Press.

Diener, E., \& Chan, M. Y. (2011). Happy people live longer: Subjective well-being contributes to health and longevity. Applied Psychology: Health and Well-Being, 3, 1-43. 
Ehsan, A., Klaas, H. S., Bastianen, A., \& Spini, D. (2019). Social capital and health: A systematic review of systematic reviews. SSM Population Health, 8, 100425. https://doi.org/10.1016/j.ssmph.2019.100425.

Elgar, F. J., Davis, C. G., Wohl, M. J., Trites, S. J., Zelenski, J. M., \& Martin, M. S. (2011). Social capital, health and life satisfaction in 50 countries. Health \& Place, 17, 1044-1053. https://doi.org/10.1016/ j.healthplace.2011.06.010.

Gilbert, K. L., Quinn, S. C., Goodman, R. M., Butler, J., \& Wallace, J. (2013). A meta-analysis of social capital and health: A case for needed research. Journal of Health Psychology, 18, 1385-1399. https://doi.org/10.1177/1359105311435983.

Greenfield, E. A., \& Marks, N. F. (2004). Formal volunteering as a protective factor for older adults psychological well-being. The Journals of Gerontology: Series B, Psychological Sciences and Social Sciences, 59(5), S258-S264. https://doi.org/10.1093/geronb/59.5.s258.

Hussen, S. A., Tsegaye, M., Argaw, M. G., Andes, K., Gillard, D., \& del Rio, C. (2014). Spirituality, social capital and service: Factors promoting resilience among expert patients living with HIV in Ethiopia. Global Public Health, 9, 286-298. https://doi.org/10.1080/ 17441692.2014 .880501$.

Imai, T., Osada, H., \& Nishimura, Y. (2012). The reliability and validity of a new scale for measuring the concept of Ikigai (Ikigai-9). Japanese Journal of Public Health, 59, 433-440 (In Japanese).

Ishizaki, T., Watanabe, S., Suzuki, T., Shibata, H., \& Haga, H. (2000). Predictors for functional decline among nondisabled older Japanese living in a community during a 3-year follow-up. Journal of the American Geriatrics Society, 48, 1424-1429. https://doi.org/10. 1111/j.1532-5415.2000.tb02632.x.

Japanese Association of Preventive Medicine for Adult Disease (JAPA) (n.d.). Kenko kanrisi [Specialists of health management]. https:// www.healthcare.or.jp. Accessed: December 8, 2020. (In Japanese).

Kashaniyan, F., \& Khodabakhshi-Koolaee, A. (2015). Effectiveness of positive psychology group interventions on meaning of life and life satisfaction among older adults. Elderly Health Journal, 1(2), 6874.

Koivumaa-Honkanen, H., Honkanen, R., Viinamäki, H., Heikkilä, K., Kaprio, J., \& Koskenvuo, M. (2000). Self-reported life satisfaction and 20-year mortality in healthy Finnish adults. American Journal of Epidemiology, 152(10), 983-991. https://doi.org/10.1093/aje/152.10.983.

Koizumi, M., Ito, H., Kaneko, Y., \& Motohashi, Y. (2008). Effect of having a sense of purpose in life on the risk of death from cardiovascular diseases. Journal of Epidemiology, 18(5), 191-196. https:// doi.org/10.2188/jea.je2007388.

Komiyama, Y. (2012). A basic direction for comprehensive implementation of national health promotion. Ministry of Health, Labour and Welfare. http://www.pbhealth.med.tohoku.ac.jp/japan21/pdf/ kenkounippon21 01e.pdf. Accessed: December 8, 2020.

Krause, N. (2009). Meaning in life and mortality. The Journals of Gerontology: Series B, Psychological Sciences and Social Sciences, 64B(4), 517-527. https://doi.org/10.1093/geronb/gbp047.

Leung, A., Kier, C., Fung, T., Fung, L., \& Sproule, R. (2011). Searching for happiness: The importance of social capital. Journal of Happiness Studies, 12, 443-462.

Ministry of Health, Labour and Welfare. (2012). A basic direction for comprehensive implementation of national health promotion. Ministerial Notification No. 430, https://www.mhlw.go.jp/file/06Seisakujouhou-10900000-Kenkoukyoku/0000047330.pdf. Accessed: December 8, 2020.

Moore, S., \& Kawachi, I. (2017). Twenty years of social capital and health research: A glossary. Journal of Epidemiology and Community Health, 71, 513-517. https://doi.org/10.1136/jech-2016-208313.

Musich, S., Wang, S. S., Kreamer, S., Hawkins, K., \& Wicker, E. (2018). Purpose in life and positive health outcomes among older adults. Population Health Management, 21, 139-147. https://doi.org/10. 1089/pop.2017.0063.
National Institute of Health and Nutrition (NIHN). (2013). Health Japan 21. http://www.nibiohn.go.jp/eiken/kenkounippon21/en/ kenkounippon21/. Accessed: December 8, 2020.

Porta, M. (Ed.). (2014). A dictionary of epidemiology (6th ed.). Oxford University Press.

Putnam, R. D. (1993). Making democracy work: Civic traditions in modern Italy. Princeton University Press.

Rodríguez-Pose, A., \& von Berlepsch, V. (2014). Social capital and individual happiness in Europe. Journal of Happiness Studies, 15, 357-386.

Roepke, A. M., Jayawickreme, E., \& Riffle, O. (2014). Meaning and health: A systematic review. Applied Research Quality Life, 9, 1055-1079.

Sin, N. L., \& Lyubomirsky, S. (2009). Enhancing well-being and alleviating depressive symptoms with positive psychology interventions: A practice-friendly meta-analysis. Journal of Clinical Psychology, 65(5), 467-487. https://doi.org/10.1002/jclp.20593.

Sone, T., Nakaya, N., Ohmori, K., Shimazu, T., Higashiguchi, M., Kakizaki, M., Kikuchi, N., Kuriyama, S., \& Tsuji, I. (2008). Sense of life worth living (ikigai) and mortality in Japan: Ohsaki study. Psychosomatic Medicine, 70, 709-715. https://doi.org/10.1097/ PSY.0b013e31817e7e64.

Steptoe, A. (2019). Happiness and health. Annual Review of Public Health, 40, 339-359. https://doi.org/10.1146/annurev-publhealth040218-044150.

Suzuki, T., \& Shibata, H. (2003). An introduction of the Tokyo metropolitan institute of gerontology longitudinal interdisciplinary study on aging (TMIG-LISA, 1991-2001). Geriatrics and Gerontology International, 3, S1-S4. https://doi.org/10.1111/j.1444-0594.2003.00088.x.

Takahashi, S., Ishiki, M., Kondo, N., Ishiki, A., Toriyama, T., Takahashi, S., Moriyama, H., Ueno, M., Shimanuki, M., Kanno, T., Oki, T., \& Tabata, K. (2015). Health effects of a farming program to foster community social capital of a temporary housing complex of the 2011 great East Japan earthquake. Disaster Medicine and Public Health Preparedness, 9, 103-110. https://doi.org/10.1017/dmp.2015.6.

Tanno, K., Sakata, K., Ohsawa, M., Onoda, T., Itai, K., Yaegashi, Y., Tamakoshi, A., \& JACC Study Group. (2009). Associations of ikigai as a positive psychological factor with all-cause mortality and cause specific mortality among middle-aged and elderly Japanese people: Findings from the Japan collaborative cohort study. Journal of Psychosomatic Research, 67(1), 67-75. https:// doi.org/10.1016/j.jpsychores.2008.10.018.

Udagawa, K., Miyoshi, M., \& Yoshiike, N. (2008). Mid-term evaluation of Health Japan 21: Focus area for the nutrition and diet. Asia Pacific Journal of Clinical Nutrition, 17(Suppl 2), 445-452.

Villalinga-Olives, E., \& Kawachi, I. (2015). The measurement of bridging social capital in population health research. Health \& Place, 36, 47-57. https://doi.org/10.1016/j.healthplace.2015.09.002.

Winkelmann, R. (2009). Unemployment, social capital, and subjective well-being. Journal of Happiness Studies, 10, 421-430.

Wood, A. M., \& Joseph, S. (2010). The absence of positive psychological (eudemonic) well-being as a risk factor for depression: A ten year cohort study. Journal of Affective Disorders, 122(3), 213-217. https://doi.org/10.1016/j.jad.2009.06.032.

Xu, J., \& Roberts, R. E. (2010). The power of positive emotions: it's a matter of life or death-Subjective well-being and longevity over 28 years in a general population. Health Psychology, 29(1), 9-19. https://doi.org/10.1037/a0016767.

Zou, T., Su, Y., \& Wang, Y. (2018). Examining relationships between social capital, emotion experience and life satisfaction for sustainable community. Sustainability, 10, 2651. https://doi.org/10.3390/ su10082651.

Publisher's Note Springer Nature remains neutral with regard to jurisdictional claims in published maps and institutional affiliations. 